\title{
$\beta$-Caryophyllene Inhibits Cell Proliferation through a Direct Modulation of CB2 Receptors in Glioblastoma Cells
}

\author{
Natasha Irrera ${ }^{1}$, Angela D'Ascola ${ }^{1}{ }^{\circledR}$, Giovanni Pallio $^{1}{ }^{1}$, Alessandra Bitto $^{1}$, Federica Mannino ${ }^{1}$, \\ Vincenzo Arcoraci ${ }^{1}$, Michelangelo Rottura ${ }^{1}$, Antonio Ieni ${ }^{2} \mathbb{D}$, Letteria Minutoli ${ }^{1}$, \\ Daniela Metro $^{3}$, Mario Vaccaro ${ }^{1}$ (1), Domenica Altavilla ${ }^{3}$ and Francesco Squadrito ${ }^{1, *(1)}$ \\ 1 Department of Clinical and Experimental Medicine, University of Messina, c/o AOU Policlinico G. Martino, \\ Via C. Valeria Gazzi, 98125 Messina, Italy; nirrera@unime.it (N.I.); adascola@unime.it (A.D.); \\ gpallio@unime.it (G.P.); abitto@unime.it (A.B.); fmannino@unime.it (F.M.); varcoraci@unime.it (V.A.); \\ rotturamichelangelo@gmail.com (M.R.); lminutoli@unime.it (L.M.); vaccaro@unime.it (M.V.) \\ 2 Department of Human Pathology in Adult and Developmental Age "Gaetano Barresi", \\ University of Messina, c/o AOU Policlinico G. Martino, Via C. Valeria Gazzi, 98125 Messina, Italy; \\ aieni@unime.it \\ 3 Department of Biomedical and Dental Sciences and Morphofunctional Imaging, University of Messina, \\ c/o AOU Policlinico G. Martino, Via C. Valeria Gazzi, 98125 Messina, Italy; dmetro@unime.it (D.M.); \\ daltavilla@unime.it (D.A.) \\ * Correspondence: fsquadrito@unime.it
}

Received: 13 April 2020; Accepted: 20 April 2020; Published: 23 April 2020

\begin{abstract}
Glioblastomas are aggressive cancers characterized by uncontrolled proliferation and inflammation. b-caryophyllene (BCP) is a cannabinoid receptor 2 (CB2) agonist that showed an important anti-inflammatory effect through the interaction of $\mathrm{CB} 2$ and peroxisome proliferator-activated receptor gamma (PPARg) receptors. BCP effects were investigated in an in vitro model of glioblastoma. U-373 and U87, derived from a human glioblastoma, and human glioma stem-like cells (GSCs) were treated with BCP at different doses and time-points. AM360, a specific CB2 antagonist, was added $2 \mathrm{~h}$ before BCP treatment. BCP showed a significant anti-proliferative effect, reducing cell viability, inhibiting cell cycle, and increasing apoptosis, as demonstrated by Tunel assay, caspase- 3 and caspase -9 activation. In addition, the pro-apoptotic BAX expression was increased, whereas the anti-apoptotic Bcl-2 expression was reduced. Treatment with BCP decreased Beclin-1, LC3 and p62/SQSTM1 expression, indicating a possible switch of autophagy to apoptosis. BCP's anti-inflammatory effect was demonstrated by NF- $\mathrm{KB}$ reduction, PPARg activation and TNF-a decrease; $\mathrm{BCP}$ significantly reduced Jun N-Terminal Kinase (JNK) expression as a consequence of TNF- $\alpha$ inhibition. AM360 abrogated BCP effects, thus demonstrating the BCP mechanism of action through the $\mathrm{CB} 2$ receptor. These findings let us hypothesize that $\mathrm{BCP}$ may act as a tumor suppressor in glioblastoma, acting on CB2 receptor and modulating JNK.
\end{abstract}

Keywords: glioblastoma; $\beta$-caryophyllene; CB2 receptor; apoptosis; inflammation

\section{Introduction}

Glioblastomas (GBMs) are malignant tumors of the central nervous system that may appear as de novo cancers, primary GBMs, or may develop from glioma [1]. GBMs are particularly aggressive cancers characterized by an exaggerated proliferation and uncontrolled angiogenesis, thus promoting tumor growth. Different types of cancers, including glioblastomas, showed the activation of Nuclear Factor kappa B (NF-kB) and mitogen-activated protein kinase (MAPK) pathways, which often stimulates cell 
growth and proliferation [2]. NF- $\mathrm{KB}$ is highly expressed in gliomas and may worsen the prognosis of the disease [3]. The transcription factor NF- $\mathrm{kB}$ regulates the expression of genes involved in inflammatory response, thus releasing pro-inflammatory cytokines [4]; increased levels of pro-inflammatory cytokines have also been shown in gliomas, which may be considered as a pro-inflammatory neoplasia [5].

Treatment of GBM is currently based on surgical removal followed by radiotherapy and the administration of temozolomide, as adjuvant therapy [6]. However, the median survival of patients is of 5 years following initial diagnosis. For this reason, new therapeutic strategies are necessary to improve the prognosis of the disease as well as the quality of life of patients. Cannabinoid specific receptors CB1 and cannabinoid receptor 2 (CB2), involved in the control of cell proliferation, differentiation and survival, are distributed in brain and are expressed in different cell types, such as astrocytes, microglia and glioblastoma cells [7]; therefore, targeting CB receptors might represent an interesting strategy. Cannabinoids are constituents of the plant Cannabis sativa and cannabis constituents have been used in traditional medicine thanks to their curative properties. Among them, phytocannabinoids, cannabinol, cannabidiol (CBD), cannabigerol or $\beta$-caryophyllene (BCP) $[8,9]$ have been extracted to avoid psychoactive activity related to cannabinoid $\Delta 9$-tetrahydrocannabinol (THC). In vivo studies described the cannabinoids mechanism of action on cancers, indicating that $\mathrm{CB}$ agonists act (i) inducing cell death processes such as apoptosis and/or autophagy and (ii) inhibiting cell proliferation [10]. BCP is a bicyclic sesquiterpene whose possible efficacy has been yet described on cancer cells [11]. In addition, an in vivo study demonstrated that BCP treatment may modulate inflammation through a crosstalk between CB2 receptor and peroxisome proliferator-activated receptor gamma (PPAR- $\gamma$ ) [12]. However, the effects of $\mathrm{BCP}$ on glioblastoma have not been yet deeply investigated and the exact mechanism of action of $\mathrm{BCP}$ has to be deeply explained. Therefore, the aim of this study was to investigate $\mathrm{BCP}$ effects in an in vitro model of glioblastoma.

\section{Results}

\subsection{BCP Reduces Cell Viability}

BCP cytotoxicity was evaluated by incubating U373 with increasing concentrations, starting from 2.5 to $60 \mu \mathrm{g} / \mathrm{mL}$. As shown in Figure 1 (panel A), a reduction in cell viability was observed when cells were treated with BCP concentrations up to $60 \mu \mathrm{g} / \mathrm{mL}$. The most effective dose was $60 \mu \mathrm{g}$. Notably, cell viability was reduced to about $70 \%$ with $20 \mu \mathrm{g} / \mathrm{mL}$ and $50 \%$ with $30 \mu \mathrm{g} / \mathrm{mL} \mathrm{BCP}$ at $24 \mathrm{~h}$, respectively (Figure $1 \mathrm{~A}$ ). To examine the anti-proliferative effects, cells were treated with 10 or $20 \mu \mathrm{g} / \mathrm{mL}$ concentrations of BCP for indicated time intervals. The results of MTT (3-(4,5-dimethylthiazol-2-yl)-2,5-diphenyltetrazolium bromide) assay showed that BCP suppressed cell proliferation in these glioma cells in a dose- and time-dependent manner (Figure 1, panel B).

A p53 wild-type glioma cell line (U87) was also used to evaluate potential differences compared to U373 cells which are p53 mutant cell line. As shown in Figure 1 (panels C and D), BCP exhibited both cytotoxic and anti-proliferative effects in these glioma cells, resulting effective at slightly lower doses. Indeed, cell viability was reduced to about $60 \%$ with $20 \mu \mathrm{g} / \mathrm{mL}$ and $40 \%$ with $30 \mu \mathrm{g} / \mathrm{mL} \mathrm{BCP}$ at $24 \mathrm{~h}$ and $5 \mu \mathrm{g} / \mathrm{mL} \mathrm{BCP}$ was able to suppress cell proliferation until $72 \mathrm{~h}$. 
A

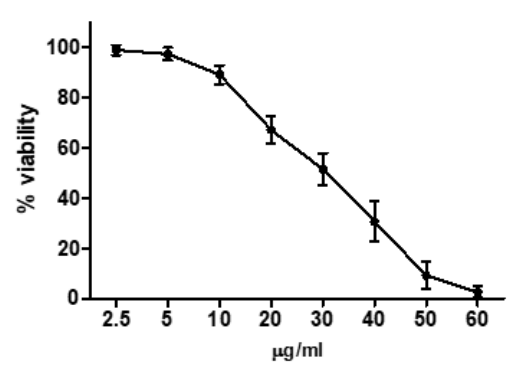

C

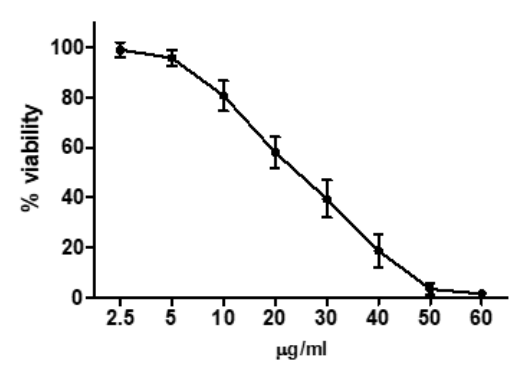

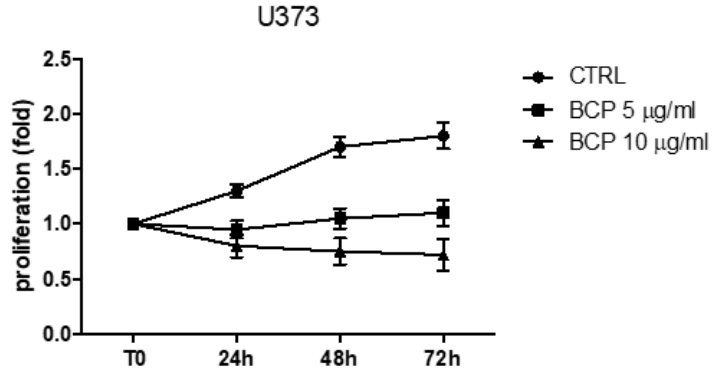

D

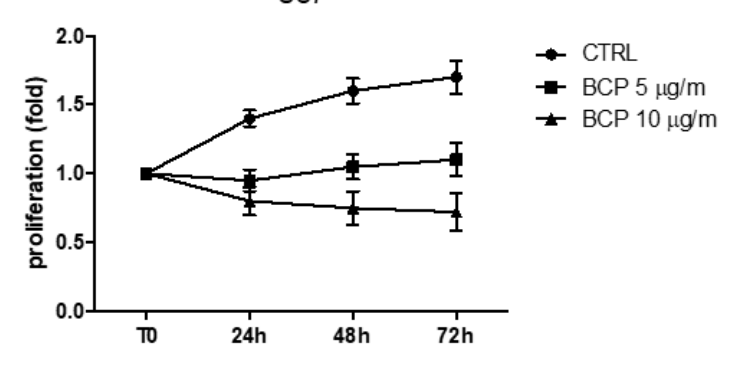

Figure 1. Dose response curve of cell viability assessed in U373 (panel A) and U87 (panel C) cells treated with b-caryophyllene (BCP). Values are expressed as percentage of reduction of viability with respect to the untreated control. Cell proliferation evaluation at T0, 24, 48 and $72 \mathrm{~h}$ in U373 (panel B) and U87 (panel D) cells treated with BCP. Values are expressed as fold change of viability with respect to the untreated control at T0.

\subsection{BCP Induces Apoptotic Cell Death}

The apoptotic cell death was first determined with Tunel assay. The results show that BCP treatment caused a marked increase in cell death through apoptosis following $24 \mathrm{~h}$ of treatment (Figure 2, panels A-D). In particular, the observed increase was of about $20 \%$ and $40 \%$ with 20 and $30 \mu \mathrm{g} / \mathrm{mL} \mathrm{BCP}$, respectively (Figure 2, panel E). Moreover, BCP treatment significantly increased caspase-3 and caspase-9 mRNA expression (Figure 3, panels A and B), thus providing evidence of apoptotic process activation. To further confirm these results, B-cell lymphoma (BCL)-2 and BCL Associated X (BAX) mRNA expression was examined, as markers of apoptosis. Consistent with the caspases results, BCP treatment induced a marked decrease in BCL-2 mRNA expression and increased BAX mRNA levels in U373 cells in a dose-dependent manner (Figure 3, panels C and D). In addition, Beclin-1, Microtubule-associated protein 1A/1B-light chain 3 (LC3) and p62/Sequestosome 1 (SQSTM1) were evaluated as markers of autophagy. Treatment with BCP resulted in a reduction of Beclin-1 and LC3 and p62/SQSTM1 expression compared to untreated U373 cells, indicating a possible switch of autophagy to apoptosis triggered by BCP (Figure 3, panels E-G). 
CTRL

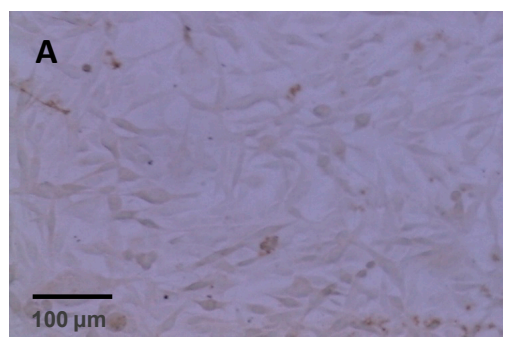

$\mathrm{BCP} 30$

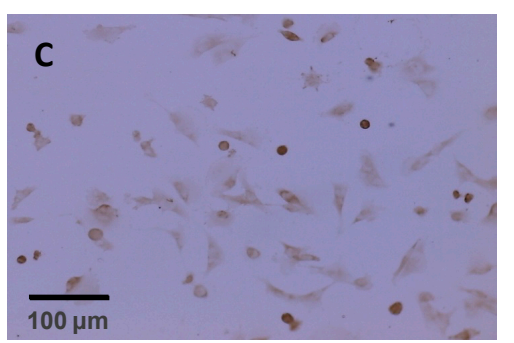

BCP 20
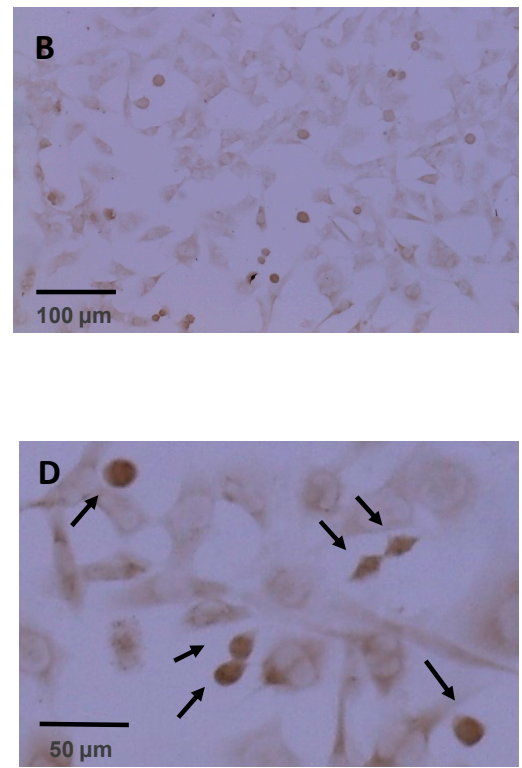

E

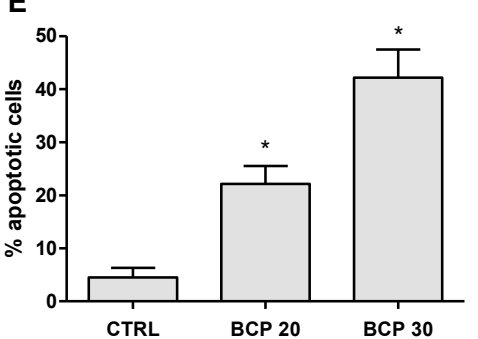

Figure 2. Effect of BCP on apoptosis induction in U373 cells. The detection of apoptosis was assessed by TUNEL (Terminal deoxynucleotidyl transferase dUTP nick end labeling) assay. In the images (panels A-C; scale bar $=100 \mu \mathrm{m}$ ), brown color reaction indicates cells that underwent apoptosis. Panel D shows cells at higher magnification (scale bar $=50 \mu \mathrm{m}$ ) and TUNEL—positive cells are indicated by arrows. Quantitative results are presented as a percentage of TUNEL-positive (panel E). The data are expressed as the mean $\pm \mathrm{SD} ;{ }^{*} p<0.001 \mathrm{vs}$. the control. 
A

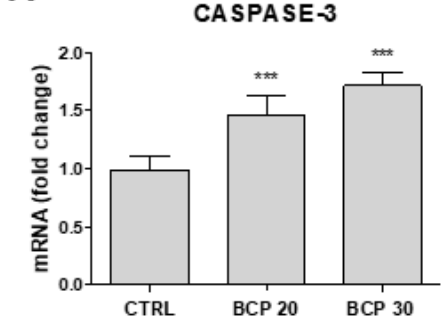

E

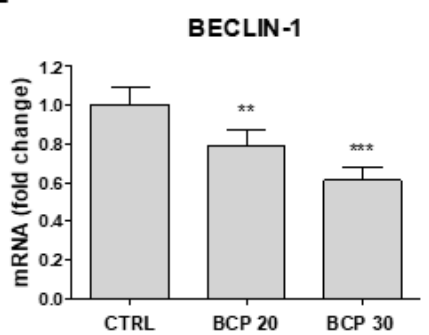

B

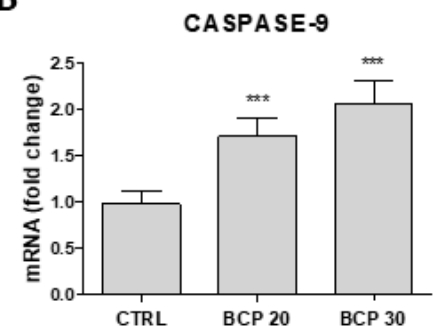

F

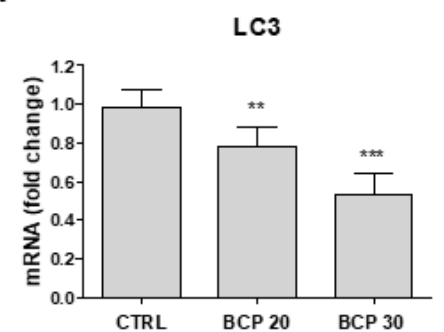

C

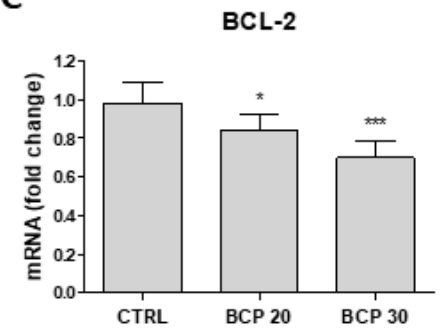

G

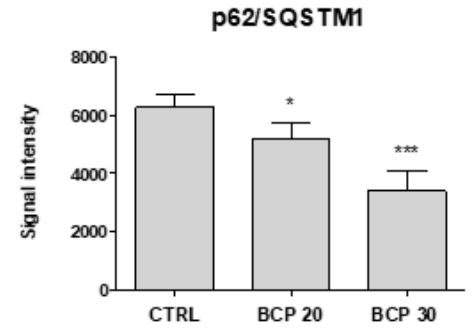

D

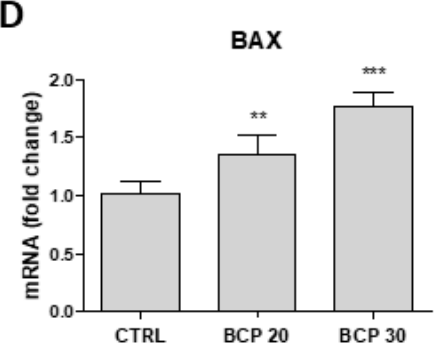

p62

$\beta$-actin

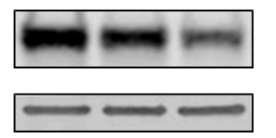

Figure 3. Effect of BCP on caspase-3 (A), caspase-9 (B), BCL-2 (C), BAX (D), BECLIN-1 (E), and LC3 (F) mRNA expression in U373 cells. (G) The graph represents p62/SQSTM1 protein expression. mRNA levels are calculated according to the $2^{-\Delta \Delta C t}$ method as fold change relative to normal controls. Treatment with BCP significantly reduced p62 protein expression compared to the control; the blots were quantified by densitometric analysis. The data are expressed as signal intensity and as means $\pm \mathrm{SD} ;{ }^{*} p<0.05,{ }^{* *} p<0.01, * * * 0<0.001$ vs. the control. 


\subsection{BCP Plays an Anti-Inflammatory Activity through the Modulation of NF- $\kappa B$ and PPAR- $\gamma$}

In the present experiment, $\mathrm{BCP}$ treatment caused a significant reduction in phosphorylated NF- $\mathrm{KB}$ (p-NF- $\mathrm{kB}$ ) and, in contrast, a significant increase in PPAR- $\gamma$ at both doses of 20 and $30 \mu \mathrm{g} / \mathrm{mL}$ (Figure 4, panels A and B). In addition, Tumor Necrosis Factor alpha (TNF- $\alpha$ ) mRNA expression was significantly reduced following BCP treatment at the dose of both 20 and $30 \mu \mathrm{g} / \mathrm{mL}$, as a probable consequence of NF- $K B$ reduction and PPAR- $\gamma$ activation (Figure 4, Panel C).
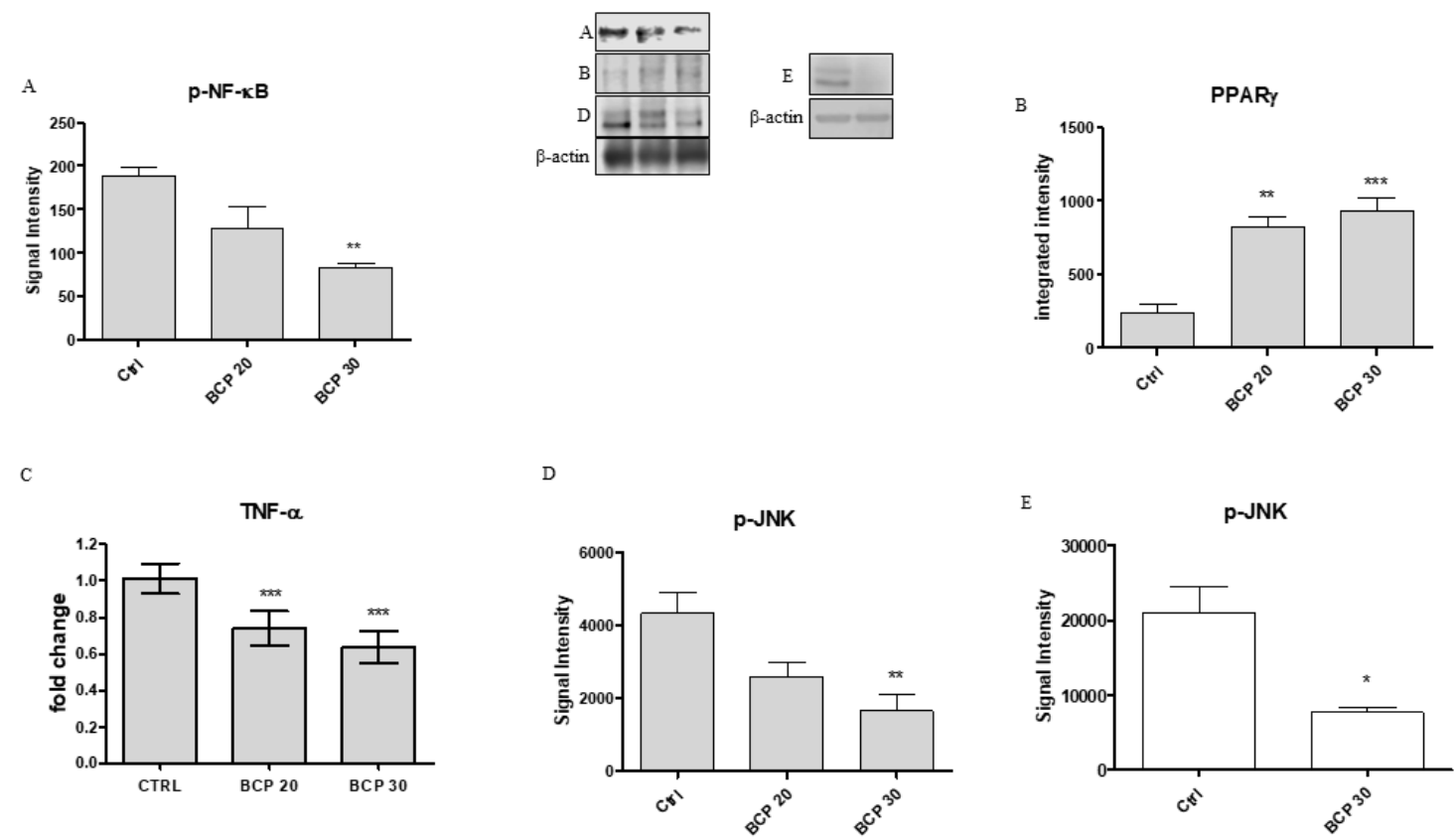

Figure 4. The graphs represent the protein expression of pNF-kB (A), PPAR $\gamma(\mathbf{B}), \mathrm{pJNK}(\mathbf{D}, \mathbf{E})$ and mRNA expression of TNF- $\alpha(C)$ from U373 cells untreated and treated with BCP at the doses of 20 and $30 \mu \mathrm{g} / \mathrm{mL}$ and U87 cells (E) untreated and treated with BCP at the dose of $30 \mu \mathrm{g} / \mathrm{mL}$. After the densitometric analysis, the data are expressed as signal intensity and as means \pm SD. ${ }^{*} p<0.05,{ }^{* *} p<$ $0.01,{ }^{* * *} p<0.001$, vs. the control.

\subsection{BCP Carries Out an Anti-Proliferative Effect through Jun N-Terminal Kinase (JNK) Reduction}

We investigated the involvement of JNK in the anti-proliferative effects of BCP by Western Blot analysis. U373 cells showed high levels of phosphorylated JNK (p-JNK), whereas the treatment with BCP significantly reduced JNK expression, particularly at the concentration of $30 \mu \mathrm{g} / \mathrm{mL}$ (Figure 4, Panel D). Similar results were obtained using the p53 WT cells, U87, which revealed that BCP treatment at the dose of $30 \mu \mathrm{g} / \mathrm{mL}$ significantly reduced p-JNK expression compared to untreated cells (Figure 4, Panel E).

\subsection{AM630, a CB2 Antagonist, Abrogates BCP Effects}

To evaluate if the anti-proliferative effect of $\mathrm{BCP}$ was mediated by CB2 activation in the U373 glioblastoma cell line, we treated cells with a specific CB2 receptor antagonist, AM630. The concomitant incubation of BCP at the dose of $30 \mu \mathrm{g} / \mathrm{mL}$ and AM630 reduced caspase- 3 activation and partially restored cell viability (Figure 5, panels A and B). In addition, AM360 abrogated BCP effects on both PPAR $\gamma$ and JNK expression, restoring the protein levels of untreated cancer cells. Therefore, this experimental paradigm confirms the $\mathrm{BCP}$ mechanism of action, thus demonstrating that $\mathrm{BCP}$ effects were mediated by $\mathrm{CB} 2$ receptor (Figure 5, panels $\mathrm{C}$ and D). 
A

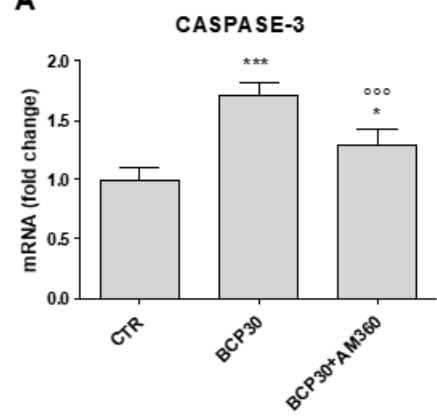

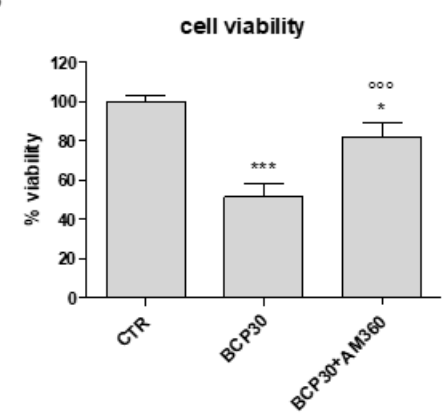

C

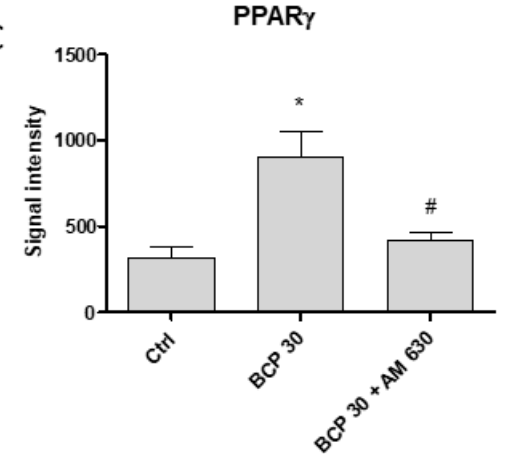

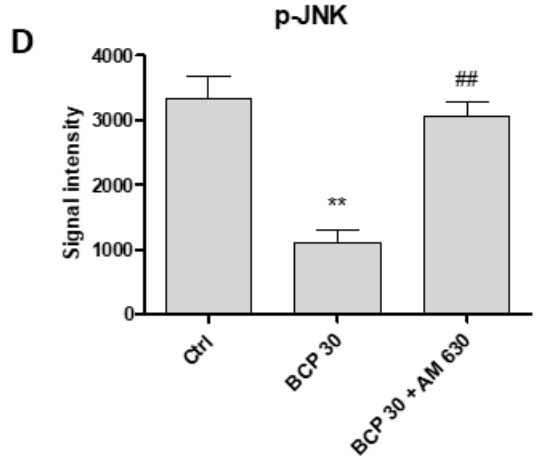

Figure 5. Graphs represent caspase-3 gene expression (A), cell viability (B), and the protein expression of PPAR $\gamma($ C) and pJNK (D) in U373 cells untreated and treated with BCP at the dose $30 \mu \mathrm{g} / \mathrm{mL}$ and $\mathrm{BCP}(30 \mu \mathrm{g} / \mathrm{mL})+\mathrm{AM} 630$, cannabinoid receptor 2 (CB2) receptor antagonist. After densitometric analysis data are expressed as signal intensity and means $\pm \mathrm{SD}$. ${ }^{*} p<0.05$ and ${ }^{* *} p<0.01 \mathrm{vs}$. the control and BCP+AM630; ${ }^{\circ \circ 0} p<0.001$ vs. ВCP $30 ;{ }^{\#} p<0.05$ and ${ }^{\# \#} p<0.01$ vs. ВСР30. ${ }^{* * *} p<0.001$.

\section{6. $\beta$-Caryophyllene Reduces the Proliferation of Glioma Stem Cells and Inhibits Cell Cycle}

Glioma stem cells (GSCs) were used to confirm BCP efficacy. The expression of two glioma stem cells-specific markers, CD133 and OCT4, were assayed in GSCs at the passage 6, the last culture passage used in the experiments, to confirm GSCs gene expression profile. Two specific bands of about $370 \mathrm{bp}$ and $280 \mathrm{bp}$ were detected for CD133 and OCT4 PCR products, respectively in agarose gel. Detection of specific bands following Western Blot analysis indicated that the cells were able to express specific stem cell markers (Figure S1). These results demonstrated that GSCs still maintained stem cell phenotypic profile at passage 6 , therefore they were useful to evaluate BCP effects.

BCP significantly reduced cell viability and proliferation compared to untreated GSCs (Figure 6, panels A and B). BCP anti-proliferative effect was also confirmed by the inhibition of the cell cycle. In fact, BCP treatment significantly down-regulated Cyclin D1 and its cyclin-dependent kinase (CDK) 4 in both U373 glioblastoma cell line and in glioma stem cells (Figure 6, panels C-F). These results suggest that BCP regulates the uncontrolled cell cycle both in U373 glioblastoma cells and in the more resistant glioma stem cells. 
A

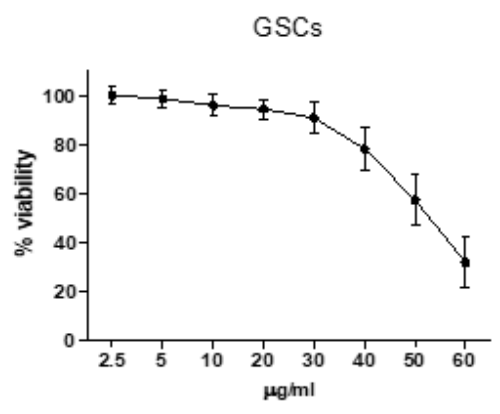

C

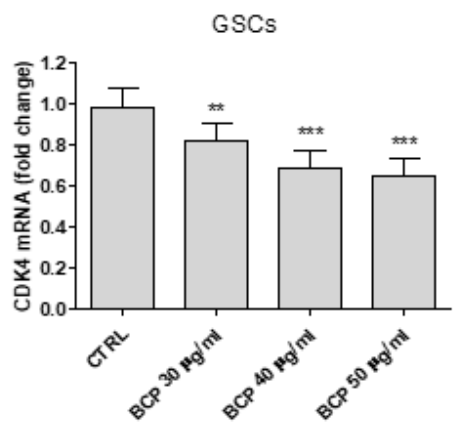

E

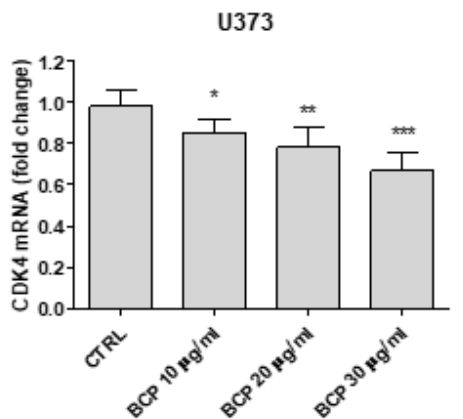

B

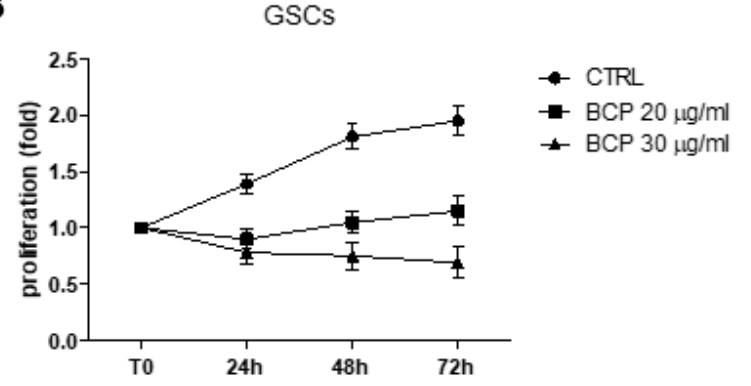

D

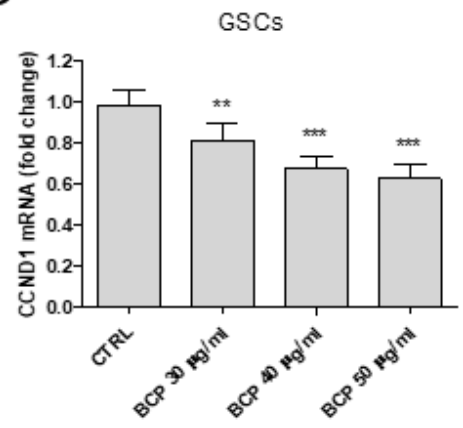

$\mathbf{F}$

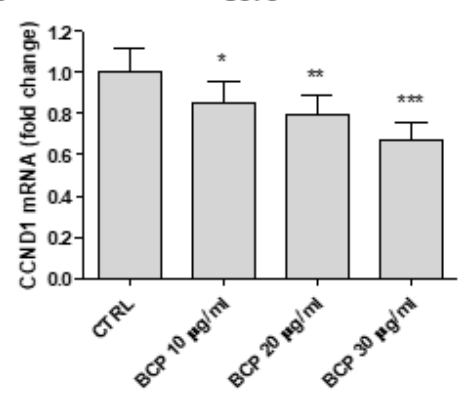

Figure 6. Dose response curve of cell viability assessed in GSCs treated with BCP (panel A). Values are expressed as percentage of reduction of viability with respect to the untreated control. Cell proliferation evaluation at T0, 24, 48 and $72 \mathrm{~h}$ in GSCs treated with BCP (panel B). Values are expressed as fold change of viability with respect to the untreated control at T0. Evaluation of CDK4 an CCND1 mRNA in GSCs and U373 cells treated with BCP at different doses (panels C-F). Data are calculated according to the $2^{-\Delta \Delta \mathrm{Ct}}$ method as fold change relative to normal controls and expressed as means $\pm \mathrm{SD} .{ }^{*} p<0.05$, ${ }^{* *} p<0.01,{ }^{* * *} p<0.001$, vs. the control.

\section{Discussion}

The identification of cannabinoid receptors in the central nervous system led to the hypothesis that targeting a cannabinoid receptor might be used as a therapeutic approach. High-grade gliomas, including glioblastomas, express high levels of CB2 receptors and their expression often correlates with malignancy [7]. The canonical signaling pathway for CBRs involves their coupling with Gi/0 and normally results in an overall inhibitory signal. Other pathways that can be activated by the binding of cannabinoids to CBRs involve the enzymes PI3 kinase, esphingomyelinase, and phospholipase C [13]. CB2R activation has been shown to mediate an inhibitory effect on the activation, cell motility and secretion of inflammatory mediators.

$\beta$-caryophyllene is a natural CB2 receptor agonist that potentially inhibits cell survival proteins [11] and also modulates the activation of NFKB and PPAR $\gamma$; thus, it has been tested to reduce proliferation and activate apoptosis in glioblastoma. To investigate this issue, U373 and U87 cells were used: U373 is a human glioblastoma cell line with a p53 mutation in codon 273 of the p53 gene and cannot 
transactivate a reporter gene containing a p53-responsive transcriptional promoter, eventually causing tumor progression for p53 loss of function [14]. U87 cells are derived from glioma with a wild-type p53 and served as control to dissect out the effect of BCP in reducing cell proliferation in an abnormal (U373) and normal (U87) proliferative status. Following a short ( $24 \mathrm{~h}$ ) and longer (72 h) incubation with BCP, a significant anti-proliferative effect was observed in both cell lines. In particular, BCP was only slightly more effective in U87, suggesting that the inhibitory effect is not mainly linked to p53 activation status. Scientific evidences described the role of glioma-derived stem-like cells in gliomas whose presence is a predictive factor of high malignancy $[15,16]$; they contribute to heterogeneity of tumors and are particularly resistant to therapies. Therefore, GSCs were used in this study to confirm BCP anti-proliferative efficacy. BCP reduced cell viability in glioma-derived stem-like cells, thus demonstrating that this therapeutic approach might also be effective in conditions of resistance. BCP also modulated cell cycle both in GSCs and in the U373 cell line, reducing Cyclin D1 and CDK4 expression. This is a relevant piece of data since cell cycle is uncontrolled in tumors and targeting cell cycle, using BCP, may be an interesting therapeutic approach in aggressive cancers such as glioblastomas. The results obtained in GSCs are therefore of paramount importance because they confer to BCP a more powerful translational potential. However, it could be argued that GSCs might lose their characteristic phenotype, thus weakening our scientific message. To check for this bias, we evaluated two glioma stem-cell-specific markers, CD133 and OCT4, that were studied in GSCs at the passage 6, the last culture passage used in our experiments. The results clearly show that GSCs still maintained their stem cell phenotypic profile at passage 6 , thus ruling out the loss of aggressiveness stigmata that make it the closest experimental paradigm to the clinical setting.

The inhibitory effect of BCP led us to hypothesize the involvement of a pathway that is, at least in part, unrelated to cell survival, as indicated by the reduced expression of p-JNK both in U373 and U87 cell lines, an effect that was reverted by using the CB2 receptor antagonist AM630. Thus, the apoptotic activation seems to be related to the activation of PPAR $\gamma$ and this might be true considering PPAR $\gamma$ as a pro-differentiating factor whose increase led the cells to a more differentiated status, cells that fail differentiation consequently die for the activation of the apoptotic process. Our results are in agreement with this hypothesis; in fact, the increased expression of effector caspases 3 and 9, and BAX has been observed as early as $24 \mathrm{~h}$ following BCP treatment also confirmed by Tunel assay. In addition, the treatment with AM630 was able to restore cell viability and reduced caspase-3 expression, confirming the involmement of $\mathrm{CB} 2$ receptor activation in the trigger of apoptosis.

Anti-apoptotic protein Bcl-2 may bind Beclin-1, whose activation regulates the autophagic process. Autophagy promotes cell survival in cancers, thus increasing tumor growth and invasiveness [17]. During autophagy, autophagosomes are produced to embed intracellular constituents and organelles, such as mitochondria. In this process, LC3 is engaged in the assembly and disassembly of microtubules [18,19]; in particular, LC3-I is converted to LC3-II through phosphatidylethanolamine (PE) conjugation and p62/SQSTM1 is considered as the LC3 substrate, thus facilitating selective degradation in the autophagy process.

In the present study, Beclin-1, LC3 and p62/SQSTM1 decrease was observed in U373 BCP-treated cells. These results demonstrate that the autophagy process was reduced following the treatment with BCP compared to untreated U-373 cancer cells and allow us to hypothesize a switch of autophagy to apoptosis, further confirming that apoptotic process was activated following the treatment with BCP. Therefore, this CB2 agonist may be considered as an anti-proliferative and protective molecule against malignant and aggressive cancers such as glioblastoma.

Apart from a direct killing effect on tumor cells, cannabinoids can also induce a significant reduction of inflammation, thereby inhibiting upstream and downstream molecules involved in inflammatory process. The curative anti-inflammatory effect of BCP was demonstrated by studying the transcription factor NF- $k B$, the activation of which causes the increase in pro-inflammatory cytokines, such as TNF- $\alpha$. In this experimental approach, U373 cells highly expressed NF- $\mathrm{B}$, whereas BCP treatment significantly reduced its expression. In addition, previous studies have indicated a possible 
crosstalk between the CB2 receptor and PPAR- $\gamma[12,20]$. The PPAR- $\gamma$ receptor activation reduces pro-inflammatory cytokine release, thus exerting an anti-inflammatory effect [21]. The obtained data demonstrate that BCP may also act through PPAR- $\gamma$; in fact, the treatment of glioblastoma cells with $\mathrm{BCP}$ significantly increased the PPAR- $\gamma$ receptor. As expected, the pro-inflammatory cytokine TNF- $\alpha$ was highly expressed in glioblastoma cells, and its expression was significantly reduced following BCP treatment, probably as a consequence of NF- $\mathrm{KB}$ reduction and PPAR- $\gamma$ activation.

Fascinatingly, it has been observed that the use of CB2 agonists may cause an accumulation of $\mathrm{TNF} \alpha$ transcripts and a decrease in protein expression [22,23]. Moreover, the JNK pathway blockade may inhibit TNF $\alpha$ [24], but TNF $\alpha$, at the same time, activates MAPK pathways, such as ERK1/2, JNK, and p38, which contributes to inflammation and cell proliferation and migration. In particular, the JNK pathway is involved in different processes, such as cell proliferation, differentiation, inflammatory response, cell survival and death.

Interestingly, scientific evidences described the JNK role in autophagy through Bcl-2 and Bcl-xL phosphorylation to active Beclin-1 [25]. In particular, as previously described, Bcl-2 and Beclin-1 reduction may be a direct consequence of JNK decrease [26]. Therefore, the results discussed so far support the idea that BCP may also regulate apoptosis and autophagy mechanisms not only through a direct modulation of $\mathrm{CB} 2$ receptors but also by JNK modulation. Several cancer therapeutics do not cross the blood-brain barrier (BBB), and other biochemical and physical factors such as the high brain efflux index (BEI), the electrostatically charged and anisotropic brain extracellular space (ECS) may block drugs crossing through the BBB. However, previous studies have already demonstrated that BCP is a small and lipid-soluble molecule (204.36 Da) that has the ability to cross the BBB $[27,28]$. This preliminary in vitro study put the basis for the possible use of BCP for the treatment of glioblastomas but an in vivo model and later clinical studies will be needed to confirm the data obtained so far.

\section{Materials and Methods}

\subsection{Cell Cultures}

U-373 MG (Uppsala; p53 mutant) and U-87 MG (p53 wild type), human glioblastoma astrocytoma cell lines derived from a malignant tumor by explant technique, were provided by ECACC cell collection (Salisbury, UK). The cells were cultured in EMEM (Eagle's Minimal Essential Medium) supplemented with $2 \mathrm{mM}$ glutamine, $1 \%$ non-essential amino acids (NEAA), $1 \mathrm{mM}$ sodium pyruvate, $10 \%$ FBS (fetal bovine serum), $1 \%$ antibiotic mixture (Sigma-Aldrich, St. Louis, MO, USA), in a 5\% $\mathrm{CO}_{2}$ humidified incubator at $37^{\circ} \mathrm{C}$. Human glioma stem-like cells (GSCs) were purchased by AcceGen Biotechnologies (USA) and cultured in the specific human glioma cancer cell medium provided by the same company. The media were renewed every 2 days and confluent cells were trypsinized, subdivided, and re-plated. In these experiments, U373 and U87 cell lines were used from passage 5 to 10 , and the GSCs were used from passage 3 to 6 . In addition, the expression of two genes associated with GSCs, CD133 and OCT4 (octamer-binding transcription factor 4), was examined at the passage 6 by RT-PCR; Western Blot analysis was also performed to evaluate protein expression. The amplified PCR products were separated on $1.5 \%$ agarose gels and visualized by ethidium bromide staining.

\subsection{Cell Treatment}

U373 cells were cultured in six well culture plates at a density of $2.5 \times 10^{5}$ cells/well. Sixteen hours after seeding, a set of plates were treated with $\beta$-caryophyllene (BCP) (Sigma-Aldrich, USA), dissolved in DMSO $(20 \mathrm{mg} / \mathrm{mL}$ ), at doses of 20 and $30 \mu \mathrm{g} / \mathrm{mL}$ (the calculated IC 50 was about $29 \mu \mathrm{g} / \mathrm{mL}$ ). In a further set of plates, a specific CB2 antagonist, AM360 (Tocris Biosciences, Abingdon, UK), was added at the dose of $100 \mathrm{nM} 2 \mathrm{~h}$ before the treatment with BCP $(30 \mu \mathrm{g} / \mathrm{mL})$. The cells underwent biochemical and molecular evaluation $24 \mathrm{~h}$ after the treatments. 


\subsection{MTT Assay}

Cell viability was evaluated by MTT assay. U373, U87 and GSCs cells were grown and treated with $\mathrm{BCP}$ at doses of $2.5,5,10,20,30,40,50$ and $60 \mu \mathrm{g} / \mathrm{mL}$ in a 48 well-plate at a density of $4 \times 10^{5}$ cells/well for $24 \mathrm{~h}$ to evaluate the cytotoxic effect. In a further set of plates, cells were seeded $2 \times 10^{5}$ cells/well and treated with BCP at doses of 5 and $10 \mu \mathrm{g} / \mathrm{mL}$ for $72 \mathrm{~h}$ to evaluate the antiproliferative effect. The tetrazolium dye MTT 3-(4,5-dimethylthiazol-2-yl)-2,5-diphenyltetrazolium bromide (Sigma Aldrich, Milan, Italy) was dissolved in sterile filtered PBS $(5 \mathrm{mg} / \mathrm{mL})$ and $40 \mu \mathrm{L}$ of the mixture was added into each well $3 \mathrm{~h}$ before the end of the $24 \mathrm{~h}$ of incubation. Medium was removed and the insoluble formazan crystals were dissolved with dimethyl sulfoxide (DMSO; $1 \mathrm{~mL} /$ well). Absorbance was measured at $550 \mathrm{~nm}$ using a spectrophotometer (Biospectrometer basic, Eppendorf, Hauppauge, NY, USA). The results were expressed as \% of cell viability compared to untreated cells and reported as means and SD.

\subsection{Tunel Assay}

The DeadEnd ${ }^{\text {TM }}$ Colorimetric TUNEL System was used to detect apoptotic cells in situ in cultured cells, according manufacturer's instructions. The systems end-label the fragmented DNA of apoptotic nuclei using a modified Tunel method. Briefly, U373 were seeded on Lab-Tek ${ }^{\circledR}$ Chamber Slides $\left(10^{4}\right.$ cell/well) and treated with BCP at doses of 20 and $30 \mu \mathrm{g} / \mathrm{mL}$ for $24 \mathrm{~h}$. Then, cells were fixed in $4 \%$ paraformaldehyde solution in PBS for $25 \mathrm{~min}$ at room temperature. After permeabilization with $0.2 \%$ of Triton-X100 solution in PBS, for $5 \mathrm{~min}$, and rinsing with PBS, cells were incubated with a mix containing biotinylated nucleotide and Terminal Deoxynucleotidyl Transferase, Recombinant, (rTdT) enzyme for $60 \mathrm{~min}$ at $37^{\circ} \mathrm{C}$. After rinsing, slides were incubated with a streptavidin HRP for $30 \mathrm{~min}$ at room temperature. Following the addition of the chromogen diaminobenzidine (DAB), apoptotic nuclei are stained dark brown and visualized with a light microscope (20× objective, Leica ICC50).

A total of 20 representative images were investigated for each sample and the number of apoptotic cell was determined by counting the total number of nuclei per image area and the TUNEL-positive nuclei. The results were expressed as $\%$ of apoptotic cells.

\subsection{RNA Isolation, cDNA Synthesis, and Real-Time Quantitative PCR Amplification}

Total RNA was isolated from U373 cells for RT-qPCR analysis using a Trizol Reagent Kit (Life Technologies, Monza, Italy). The first strand of cDNA was synthesized from $2.0 \mu \mathrm{g}$ total RNA using a high capacity cDNA Archive kit (Applied Biosystems, Carlsbad, CA, USA). $\beta$-actin mRNA was used as an endogenous control to allow for the relative quantification. RTqPCR was performed to evaluate the gene expression of BCL-2, BAX, caspase-3, caspase-9, TNF- $\alpha$, eclin-1, CDK4 and CCND1 using Power Up Sybr Master Mix (Applied Byosystems, CA, USA) and a QuantStudio 6 Flex Real-Time PCR System (Applied Biosystems, CA, USA). The amplified PCR products were quantified by measuring the calculated cycle thresholds (CT) of target genes and $\beta$-actin mRNA. After normalization, the mean value of the normal control target levels was chosen as the calibrator and the results were expressed according to the $2^{-\Delta \Delta C t}$ method, as a fold change relative to normal controls. The oligonucleotide sequences of the used primers are reported in Table 1. 
Table 1. Primer sequences used for RT-qPCR.

\begin{tabular}{ccc}
\hline Gene & Forward Primer $\mathbf{5}^{\prime} \mathbf{- 3}^{\prime}$ & ${\text { Reverse Primer } \mathbf{5}^{\prime} \mathbf{- 3}^{\prime}}^{\mathbf{P}^{\prime}}$ \\
ACTB & TTGTTACAGGAAGTCCCTTGCC & ATGCTATCACCTCCCCTGTGT \\
CASPASE-3 & CTGAGGCATGGTGAAGAAGGA & GTCCAGTTCTGTACCACGGCA \\
CASPASE-9 & TGCGAACTAACAGGCAAGCA & GTCTGAGAACCTCTGGTTTGC \\
BCL-2 & GAGGATTGTGGCCTTCTTTGAG & AGCCTCCGTTATCCTGGATC \\
BAX & GGACGAACTGGACAGTAACATG & GCAAAGTAGAAAAGGGCGACA \\
TNF- $\alpha$ & GATAGATGGGCTCATACCAGGG & TCTTCAAGGGCCAAGGCT \\
Beclin-1 & TGAGAGACTGGATCAGGAGG & CGCATCTGGTTTTCAACACTC \\
LC3 & AAGGCGCTTACAGCTCAATG & CTGGGAGGCATAGACCATGT \\
CDK4 & AGCCGAAACGATCAAGGAT & GCTTGACTGTTCCACCACTTG \\
CCND1 & CACCTTATTCATGGCTGAAGTC & ACAAACCTCCACTGGATGGT \\
CD133 & CTTGGCTCAGACTGGTAAATCC & CCACTTTCTCACTGATAGAG \\
OCT4 & AGAAGGATGTGGTCCGAGTG & GCACCTCAGTTTGAATGCATG \\
\hline
\end{tabular}

\subsection{Western Blot Analysis}

The cells were homogenized in RIPA buffer ( $25 \mathrm{mM}$ Tris/HCl, $\mathrm{pH} 7.4 ; 1.0 \mathrm{mM}$ EGTA; $1.0 \mathrm{mM}$ EDTA) with $1 \%$ of NP40, $0.5 \%$ of phenyl methylsulfonyl fluoride (PMSF), aprotinin, leupeptin and peptastatin $(10 \mu \mathrm{g} / \mathrm{mL}$ each) to perform protein extraction. The lysates were centrifuged at $1500 \times g$ for $15 \mathrm{~min}$ at $4{ }^{\circ} \mathrm{C}$ and the supernatant was collected for protein determination using a specific kit (Bio-Rad DC; Bio-Rad, Richmond, CA, USA). The samples were denatured in reducing buffer (62 $\mathrm{mM}$ Tris $\mathrm{pH} 6.8,10 \%$ glycerol, $2 \%$ SDS, $5 \% \beta$-mercaptoethanol, $0.003 \%$ bromophenol blue) and the proteins were separated by electrophoresis on an SDS polyacrylamide gel (10\%). Following electrophoresis, the samples were transferred onto a PVDF membrane (Amersham, Little Chalfont, UK) in a transfer buffer (39 mM glycine, $48 \mathrm{mM}$ Tris $\mathrm{pH} 8.3,20 \%$ methanol) at $200 \mathrm{~mA}$ for $1 \mathrm{~h}$. The membranes were incubated with $5 \%$ non-fat dry milk in TBS- $0.1 \%$ Tween for $1 \mathrm{~h}$ at room temperature, washed 3 times in TBS- $0.1 \%$ Tween, and incubated with primary antibodies pNF- $\mathrm{kB}$, PPAR $\gamma, \mathrm{p}-\mathrm{JNK}, \mathrm{p} 62 / \mathrm{SQSTM} 1$ (Cell Signaling, Danvers, MA), CD133 and OCT4 (Abcam, Cambridge, UK) diluted in TBS- $0.1 \%$ Tween overnight at $4{ }^{\circ} \mathrm{C}$. The day after and following 3 washes with TBS- $0.1 \%$ Tween, the membranes were incubated with secondary peroxidise-conjugated goat anti-mouse and anti-rabbit antibodies (KPL, Gaithersburg, MD, USA) for $1 \mathrm{~h}$ at room temperature. After washing, the membranes were analyzed by the enhanced chemiluminescence system (LumiGlo reserve; Seracare, Milford, MA, USA). The protein signal was detected and quantified by scanning densitometry using a bio-image analysis system (C-DiGit, Li-cor, Lincoln, NE, USA). The results were expressed as relative integrated intensity. $\beta$-actin (Cell Signalling, Danvers, MA, USA) was used to confirm equal protein loading. Whole blot can be found at Figure S2.

\subsection{Statistical Analysis}

The results are expressed as means \pm standard deviation (SD). The values reported are the result of at least five experiments performed in duplicate. All assays were repeated three times to ensure reproducibility. Different groups were analyzed by $t$-test and one-way ANOVA with Tukey's post-test for intergroup comparisons. A p value less than 0.05 was considered significant. Graphs were set using GraphPad Prism (Version 5.0 for Windows).

\section{Conclusions}

$\mathrm{BCP}$ may be considered as an inhibitor of cell proliferation mechanisms in invasive cancers such as glioblastoma thanks to the modulation of the cannabinoid system. Despite the fact that the translational potential of this study might be related to the use of human cancer cells, further investigations will be carried out to confirm the obtained in vitro results.

Supplementary Materials: The following are available online at http://www.mdpi.com/2072-6694/12/4/1038/s1, Figure S1: Evaluation of specific stem cell gene expression patterns in GSCs at passage 6, Figure S2: Whole blot (uncropped blots) for figures in main text. 
Author Contributions: Conceptualization, N.I. and A.D.; methodology, G.P., F.M. and M.R.; formal analysis, A.B., V.A. and A.I.; resources, D.A. and F.S.; data curation, A.B., L.M., D.M. and M.V.; writing original draft preparation, N.I. and A.D.; writing review and editing, N.I. and F.S.; supervision, F.S. and D.A.; project administration, N.I. and A.D.; funding acquisition, F.S. All authors have read and agreed to the published version of the manuscript.

Funding: This research received no external funding.

Acknowledgments: The study has been performed with Departmental funding assigned to F.S.

Conflicts of Interest: The authors declare no conflict of interest.

\section{References}

1. Adamson, C.; Kanu, O.O.; Mehta, A.I.; Di, C.; Lin, N.; Mattox, A.K.; Bigner, D.D. Glioblastoma multiforme: A review of where we have been and where we are going. Expert Opin. Investig. Drugs 2009, 18, 1061-1083. [CrossRef] [PubMed]

2. Abbas, M.N.; Kausar, S.; Cui, H. Therapeutic potential of natural products in glioblastoma treatment: Targeting key glioblastoma signaling pathways and epigenetic alterations. Clin Transl. Oncol. 2019. [CrossRef] [PubMed]

3. Bhat, V.; Balasubramaniyan, B.; Vaillant, R.; Ezhilarasan, K.; Hummelink, F.; Hollingsworth, F.; Wani, K.; Heathcock, L.; James, J.D.; Goodman, L.D.; et al. Aldape Mesenchymal differentiation mediated by NF-kB promotes radiation resistance in glioblastoma. Cancer Cell 2013, 24, 331-346. [CrossRef]

4. Oeckinghaus, A.; Ghosh, S. The NF-кB Family of Transcription Factors and Its Regulation. Cold Spring Harb Perspect. Biol. 2009. [CrossRef]

5. Yeung, Y.T.; McDonald, K.L.; Grewal, T.; Munoz, L. Interleukins in glioblastoma pathophysiology: Implications for therapy. Br. J. Pharmacol. 2013, 168, 591-606. [CrossRef] [PubMed]

6. Stupp, R.; Mason, W.P.; Van Den Bent, M.J.; Weller, M.; Fisher, B.; Taphoorn, M.J.; Belanger, K.; Brandes, A.A.; Marosi, C.; Bogdahn, U.; et al. Radiotherapy plus concomitant and adjuvant temozolomide for glioblastoma. N. Engl. J. Med. 2005, 352, 987-996. [CrossRef]

7. Ellert-Miklaszewska, A.; Ciechomska, I.; Kaminska, B. Cannabinoid signaling in glioma cells. Adv. Exp. Med. Biol. 2013, 986, 209-220. [PubMed]

8. Mechoulam, R. Discovery of endocannabinoids and some random thoughts on their possible roles in neuroprotection and aggression. Prostaglandins Leukot Essent Fat. Acids 2002, 66, 93-99. [CrossRef] [PubMed]

9. Gertsch, J.; Leonti, M.; Raduner, S.; Racz, I.; Chen, J.Z.; Xie, X.Q.; Altmann, K.H.; Karsak, M.; Zimmer, A. Beta-caryophyllene is a dietary cannabinoid. Proc. Natl. Acad. Sci. USA 2008, 105, 9099-9104. [CrossRef] [PubMed]

10. Rocha, F.C.; Dos Santos Júnior, J.G.; Stefano, S.C.; Da Silveira, D.X. Systematic review of the literature on clinical and experimental trials on the antitumor effects of cannabinoid in gliomas. J. Neurooncol. 2014, 116, 11-24. [CrossRef]

11. Ramachandhiran, D.; Sankaranarayanan, C.; Murali, R.; Babukumar, S.; Vinothkumar, V. $\beta$-Caryophyllene promotes oxidative stress and apoptosis in KB cells through activation of mitochondrial-mediated pathway-An in-vitro and in-silico study. Arch. Physiol. Biochem. 2019, 4, 1-15. [CrossRef] [PubMed]

12. Irrera, N.; D’Ascola, A.; Pallio, G.; Bitto, A.; Mazzon, E.; Mannino, F.; Squadrito, V.; Arcoraci, V.; Minutoli, L.; Campo, G.M.; et al. $\beta$-Caryophyllene Mitigates Collagen Antibody Induced Arthritis (CAIA) in Mice Through a Cross-Talk between CB2 and PPAR- $\gamma$ Receptors. Biomolecules 2019, 31, 326. [CrossRef] [PubMed]

13. Castillo, P.E.; Younts, T.J.; Chavez, A.E.; Hashimotodani, Y. Endocannabinoid signaling and synaptic function. Neuron 2012, 76, 70-81. [CrossRef] [PubMed]

14. Wierzbicki, M.; Sawosz, E.; Strojny, B.; Jaworski, S.; Grodzik, M.; Chwalibog, A. NF-kB-related decrease of glioma angiogenic potentiall by graphite nanoparticles and graphene oxide nanoplatelets. Sci. Rep. 2018, 8 , 14733. [CrossRef] [PubMed]

15. Singh, S.K.; Hawkins, C.; Clarke, I.D.; Squire, J.A.; Bayani, J.; Hide, T.; Henkelman, R.M.; Cusimano, M.D.; Dirks, P.B. Identification of human brain tumour initiating cells. Nature 2004, 432, 396-401. [CrossRef]

16. Holland, E.C.; Celestino, J.; Dai, C.; Schaefer, L.; Sawaya, R.E.; Fuller, G.N. Combined activation of Ras and Akt in neural progenitors induces glioblastoma formation in mice. Nat. Genet. 2000, 25, 55-57. [CrossRef]

17. Singh, R.; Cuervo, A.M. Autophagy in the cellular energetic balance. Cell Metab. 2011, 13, 495-504. [CrossRef] 
18. Kabeya, Y.; Mizushima, N.; Ueno, T.; Yamamoto, A.; Kirisako, T.; Noda, T.; Kominami, E.; Ohsumi, Y.; Yoshimori, T. LC3, a mammalian homologue of yeast Apg8p, is localized in autophagosome membranes after processing. EMBO J. 2000, 19, 5720-5728. [CrossRef]

19. Tanida, I.; Minematsu-Ikeguchi, N.; Ueno, T.; Kominami, E. Lysosomal turnover, but not a cellular level, of endogenous LC3 is a marker for autophagy. Autophagy 2005, 1, 84-91. [CrossRef] [PubMed]

20. Youssef, D.A.; El-Fayoumi,H.M.; Mahmoud, M.F. Beta-caryophyllene alleviates diet-induced neurobehavioral changes in rats: The role of CB2 and PPAR- $\gamma$ receptors. Biomed. Pharm. 2019, 110, 145-154. [CrossRef]

21. Pistis, M.; O'Sullivan, S.E. The Role of Nuclear Hormone Receptors in Cannabinoid Function. Adv. Pharm. 2017, 80, 291-328.

22. Puffenbarger, R.A.; Boothe, A.C.; Cabral, G.A. Cannabinoids inhibit LPS-inducible cytokine mRNA expression in rat microglial cells. Glia 2000, 29, 58-69. [CrossRef]

23. Gertsch, J.; Schoop, R.; Kuenzle, U.; Suter, A. Echinacea alkylamides modulate TNF alpha gene expression via cannabinoid receptor CB2 and multiple signal transduction pathways. FEBS Lett. 2004, 577, 563-569. [CrossRef]

24. Swantek, J.L.; Cobb, M.H.; Geppert, T.D. Jun N-terminal kinase/stress-activated protein kinase (JNK/SAPK) is required for lipopolysaccharide stimulation of tumor necrosis factor alpha (TNF alpha) translation: Glucocorticoids inhibit TNF alpha translation by blocking JNK/SAPK. Mol. Cell Biol. 1997, 17, 6274-6282. [CrossRef] [PubMed]

25. Yang, J.; Yao, S. JNK-Bcl-2/Bcl-xL-Bax/Bak pathway mediates the crosstalk between Matrine-induced autophagy and apoptosis via interplay with Beclin 1. Int. J. Mol. Sci. 2015, 16, 25744-25758. [CrossRef] [PubMed]

26. Yu, H.; Wu, C.L.; Wang, X.; Ban, Q.; Quan, C.; Liu, M.; Dong, H.; Li, J.; Kim, G.Y.; Choi, Y.H.; et al. SP600125 enhances C-2-induced cell death by the switch from autophagy to apoptosis in bladder cancer cells. J. Exp. Clin. Cancer Res. 2019, 38, 448. [CrossRef]

27. Murata, K.; Matsumura, S.; Yoshioka, Y.; Ueno, Y.; Matsuda, H. Screening of beta-secretase and acetylcholinesterase inhibitors from plant resources. J. Nat. Med. 2015, 69, 123-129. [CrossRef]

28. Tian, X.; Liu, H.; Xiang, F.; Xu, L.; Dong, Z. $\beta$-Caryophyllene protects against ischemic stroke by promoting polarization of microglia toward M2 phenotype via the TLR4 pathway. Life Sci. 2019, 237, 116915. [CrossRef]

(C) 2020 by the authors. Licensee MDPI, Basel, Switzerland. This article is an open access article distributed under the terms and conditions of the Creative Commons Attribution (CC BY) license (http://creativecommons.org/licenses/by/4.0/). 